\title{
THE LOS ANGELES MEETING ON COMPUTING MACHINES
}

The Institute for Numerical Analysis of the National Bureau of Standards and the Departments of Astronomy, Engineering, and Mathematics of the University of California, Los Angeles, sponsored on July 29, 30, and 31,1948, at the University of California, Los Angeles, a series of symposia on modern calculating machinery and numerical methods. The American Mathematical Society was included among the numerous cooperating scientific and learned societies. The attendance at the symposia was approximately five hundred.

The principal address, Electronic methods of computation, was given by Professor John von Neumann, of the Institute for Advanced Study. A list of sessions on special topics, together with the papers presented to each, follows.

Present status of computing machinery developments, J. H. Curtiss, Chairman. General survey of current British developments, D. R. Hartree; General survey of current American developments, Perry Crawford.

Progress reports from principal academic research centers, Paul Morton, Chairman. The electric analog computer, G. D. McCann; Recent developments at the Harvard Computation Laboratory, H. H. Aiken; Project Whirlwind at the Massachusetts Institute of Technology, J. W. Forrester; Recent developments at project EDVAC, R. L. Snyder; Recent developments at the Institute for Advanced Study, H. H. Goldstine; Recent developments at the Illinois Institute of Technology, T. J. Higgins.

Progress reports from principal commercial research laboratories, N. E. Edelfsen, Chairman. Recent developments-UNIVAC, J. W. Mauchly; Recent developments-REEVAC, H. J. Zagar; Recent developments-E.R.A., C. B. Tompkins; Recent developments in electronic computers-I.B.M., R. R. Seeber; Recent developments, Bell Telephone Laboratories, Brockway McMillan; Recent developmentsRaytheon Laboratories, R. V. D. Campbell.

Programming for automatic digital computing machinery, John Todd, Chairman. Programming for the Dahlgren machine, C. C. Bramble; Programming for the Aberdeen machine, Franz Alt; Programming for the I.B.M. Selective Sequence Electronic Calculator, R. R. Seeber; Programming for machines under development, H. D. Huskey; Programming for machines under construction, Ida Rhodes.

The future of numerical analysis, E. F. Beckenbach, Chairman. Some unsolved problems in numerical analysis, D. R. Hartree; Numer- 
ical methods in pure mathematics, I, D. H. Lehmer; Numerical methods in pure mathematics, II, Hans Rademacher; Problems in probability and combinatorial analysis, S. M. Ulam.

Numerical analysis in applied mathematics. J. L. Barnes, Chairman. Numerical calculations in non-linear mechanics, Solomon Lefschetz; Programming in a linear structure, G. B. Dantzig; Wave propagation in hydrodynamics and electrodynamics, Bernard Friedman; Eigenvalues and eigenvectors for symmetric matrices, H. H. Goldstine.

Reports of a number of the symposia and individual papers are to be published. Enquiries and requests for copies may be addressed to the Institute for Numerical Analysis, National Bureau of Standards, University of California, Los Angeles 24, California

J. W. GREen, Associate Secretary 